\title{
Genetic variants in lipid metabolism are independently associated with multiple features of the metabolic syndrome
}

\author{
Cécile M Povel ${ }^{1,2^{*}}$, Jolanda MA Boer ${ }^{1}$, Sandra Imholz ${ }^{3}$, Martijn ET Dollé ${ }^{3}$ and Edith JM Feskens ${ }^{2}$
}

\begin{abstract}
Background: Our objective was to find single nucleotide polymorphisms (SNPs), within transcriptional pathways of glucose and lipid metabolism, which are related to multiple features of the metabolic syndrome (MetS).

Methods: 373 SNPs were measured in 3575 subjects of the Doetinchem cohort. Prevalence of MetS features, i.e. hyperglycemia, abdominal obesity, decreased HDL-cholesterol levels and hypertension, were measured twice in 6 years. Associations between the SNPs and the individual MetS features were analyzed by log-linear models. For SNPs related to multiple MetS features $(P<0.01)$, we investigated whether these associations were independent of each other.

Results: Two SNPs, CETP Ile405Val and APOE Cys112Arg, were associated with both the prevalence of low HDLcholesterol level (lle405Val $\mathrm{P}=<.0001$; Cys 112Arg P $=0.001$ ) and with the prevalence of abdominal obesity (Ile405Val P = 0.007; Cys112Arg P $=0.007$ ). For both SNPS, the association with HDL-cholesterol was partly independent of the association with abdominal obesity and vice versa.

Conclusion: Two SNPs, mainly known for their role in lipid metabolism, were associated with two MetS features i.e., low HDL-cholesterol concentration, as well as, independent of this association, abdominal obesity. These SNPs may help to explain why low HDL-cholesterol levels and abdominal obesity frequently co-occur.
\end{abstract}

Keywords: HDL-cholesterol, abdominal obesity, metabolic syndrome, CETP, APOE

\section{Introduction}

The metabolic syndrome (MetS) is a common multicomponent condition including abdominal obesity, dyslipidemia, hypertension, and hyperglycemia. It is associated with an increased risk of cardiovascular disease and type 2 diabetes [1]. A central question in understanding the MetS is why these traits cluster together [1]. The clustering may be explained by a complex physiological cascade of events, in which the occurrence of one trait initiates the occurrence of a second. Alternatively, a causative factor common to several metabolic traits may explain the clustering. This factor could be either of genetic or environmental nature [2].

\footnotetext{
* Correspondence: cecile.povel@rivm.nl

${ }^{1}$ Centre for Nutrition and Health (CVG), National Institute for Public Health and the Environment (RIVM), Bilthoven, the Netherlands

Full list of author information is available at the end of the article
}

Family and twin studies indicate that the different features of the MetS share a common genetic component [2-5]. Twin studies show that the correlation between the features of the metabolic syndrome is higher in monozygotic compared to dizygotic twins [2,6,7]. Family studies also show significant genetic correlations between the different features of the metabolic syndrome [4]. Heritability estimates of the MetS itself range from 13-27\% [3-5]. However, despite the evidence from these heritability studies, only a few single nucleotide polymorphisms (SNPs) have been linked to multiple features of the MetS[1].

Disturbances in lipid and glucose metabolism may lead to the development of one or more MetS features [8]. Therefore, genes involved in these pathways are potentially pleiotropic for multiple MetS features. In a population based cohort study, we studied 373 SNPs mainly selected from transcriptional pathways of glucose and
() Biomed Central

(c) 2011 Povel et al; licensee BioMed Central Ltd. This is an Open Access article distributed under the terms of the Creative Commons Attribution License (http://creativecommons.org/licenses/by/2.0), which permits unrestricted use, distribution, and reproduction in any medium, provided the original work is properly cited. 
lipid metabolism, and their association with multiple features of the MetS.

\section{Methods \\ Study population}

The Doetinchem Study is a population-based cohort study on lifestyle, biological risk factors and chronic diseases [9]. Between 1987 and 1991, 12404 subjects, aged 20-59, all inhabitants of Doetinchem, a town in a rural area in east of the Netherlands, were enrolled in the baseline cohort. A random sub-sample of this cohort (63\%) was invited for a second measurement round (1993-1997; response 79\%) and for a third measurement round (19982002; response 75\%). Overall, the Doetinchem Cohort comprises 4662 persons with repeated measurements.

Pregnancy and alteration in smoking behavior are factors that influence body weight and therewith the MetS. Therefore, subjects of the Doetinchem Cohort who changed their smoking habits $(\mathrm{n}=750)$, who had missing data on smoking status $(\mathrm{n}=11)$ or who where pregnant at the time of measurement $(n=122)$ were excluded from the current study. This resulted in a final study population of 3779 subjects. The second and third measurement rounds included glucose and waist circumference measurements and were used for the present study. All participants gave written informed consent and approval was obtained from local Medical-Ethical Committees.

\section{Measurements}

During each measurement round, a questionnaire on lifestyle factors was administered and anthropometric and biochemical variables were measured. For a more detailed description see [10].

During the second and third visit waist circumference was measured according to written instructions based on WHO criteria for waist measurement (1989). Waist circumference was determined to the nearest $0.5 \mathrm{~cm}$, at midway between the lowest rib and the iliac crest, with subjects in standing position and after breathing out gently. Waist circumference was measured in duplicate and the mean of the two measurements was taken. Blood pressure (BP) was measured in each round, with the subject in sitting position using a random-zero sphygmomanometer. Systolic pressure was recorded at the appearance of sounds (first-phase Korotkoff) and diastolic blood pressure was recorded at the disappearance of sounds (fifth-phase Korotkoff). BP measurement was repeated and values were averaged. During the physical examination, regular audits were performed to check adherence to the BP measuring protocol (e.g. resting time, adequate cuff size).

Non-fasting blood samples were taken by venapuncture for all subjects. Blood samples were fractionated into serum, buffy coat and erythrocytes and subsequently stored at $-30^{\circ} \mathrm{C}$ until further use. Plasma glucose levels were measured as described by Tietz [11]. HDL-cholesterol was measured in EDTA-plasma until 1998, and from 1998 onwards in serum, at the Lipid Reference Laboratory (LRL) of the university Hospital Dijkzigt in Rotterdam, using standardized enzymatic methods. Performance for enzymatic HDL-cholesterol measurements fulfilled National Cholesterol Education Program (NCEP) recommendations throughout the entire study period.

Genomic DNA was extracted from the buffy coat fraction with a salting out method. A total of 139 subjects were not eligible for genotyping, mainly because of failure to extract DNA or unavailability of buffy coats. For 3640 subjects, 401 SNP across 270 candidate genes were genotyped. A set of 383 SNP's across 253 candidate genes, passed the Illumina design tool and were genotyped with the Illumina Golden Gate assay using the Sentrix Array Matrix platform (Illumina Inc, San Diego, California) [11]. 18 Additional SNPs were genotyped by KBioscience (Hoddesdon, Hertfordshire, UK) using the KASPar chemistry, which is a competitive allele specific PCR SNP genotyping system using FRET quencher cassette oligonucleotides http://www.kbioscience.co.uk). Two SNPs (rs7412 and rs429358 in APOE) that failed in the Illumina Golden Gate assay were successfully regenotyped with Taqman assay.

A detailed description of the SNP selection procedure and a full SNP list have been published elsewhere [10]. In short, 270 candidate genes were selected by a pathwaydriven approach, with emphasis on regulatory pathways that control fatty acid, glucose, cholesterol and bile salt homeostasis [10]. The selection procedure started from the master regulator genes encoding nuclear receptors (PPARs, LXR, NR1H4) and transcription factors (SREBPs) and continued by selecting their co-activators, co-repressors and target genes. In addition, hormonal receptors (insulin receptor), their down-stream signaling proteins and genes involved in $\beta$-signaling were selected. For each gene out of these pathways, 1-7 SNPs most likely to carry functional properties were selected. For 26 SNPs genotyping was unsuccessful. In addition, 33 SNPs were not in Hardy Weinberg Equilibrium (HWE). Verification was carried out in a random sample $(n=96)$ for the eight SNPs (24\%) that deviated most strongly from HWE. All yielded the same results, except for 2 SNPs, which were therefore excluded [10]. After the exclusion of subjects with genotype failure or discordance on gender control $(n=65), 3575$ subjects were available for data analyses. Finally, data on 373 SNPs in 254 genes were available for 3575 subjects.

\section{Statistical analyses}

Abdominal obesity, low HDL-cholesterol levels, hyperglycemia and hypertension were defined according to the criteria of the AHA/NHLBI (2005)[12]. 
All analyses were performed with SAS version 9.1 (SAS Institute, INC., Cary, North Carolina). Distributions of genotypes were tested for deviation from HWE by chi-square analyses (PROC ALLELE). Associations with individual MetS features and co-occurrence of MetS features were tested. To optimize precision, subjects who changed phenotype between the two rounds were excluded. This means that subjects being e.g. hypertensive in one round and normotensive in the other round or vice versa were excluded. All analyses were adjusted for age and sex.

In a first series of analyses, the association between individual MetS features and each SNP was analyzed by log-linear models. The prevalence ratios of change per allele were calculated with an additive genetic model. To avoid chance findings we only followed up those SNPs which were related to multiple MetS features with $\mathrm{P} \leq 0.01$. We determined the expected number of SNPs related to 2 or more MetS features with $\mathrm{P}<0.01$ by chance alone and under the assumption of independent random outcomes using the following formula: Chance (P $\leq 0.01$ for SNP_1 - MetS feature_1 association) * Chance ( $\mathrm{P} \leq 0.01$ for the SNP_2 - MetS feature_2 association) *Chance (association 1 and 2 in the same direction) * number of MetS feature combinations * number of SNPs. The expected number appeared to be 0.12 $(0.01 * 0.01 * 0.5 * 6 * 373)$. Subsequently we tested whether the number of observed SNPs associated with 2 or more MetS features differed significantly from the expected 0.12 SNPs.

In our study abdominal obesity and decreased HDLcholesterol appeared to be the MetS features both associated with the same SNPs. In a second series of analyses, it was tested if the association between these SNPs and HDL-cholesterol was independent of the association with abdominal obesity, and vice versa. This was done both by adjustment and by stratification. The HDL-cholesterol analyses were adjusted for abdominal obesity and vice versa. For stratified analyses, the association with abdominal obesity was analyzed in subjects with high HDL-cholesterol levels. Low HDL-cholesterol was analyzed in subjects without abdominal obesity.

\section{Results}

Baseline characteristics among the 3575 subjects of the Doetinchem cohort are presented in table 1. Hypertension was the most prevalent MetS feature $(41.6 \%$ of the subjects were stable hypertensive and $32.3 \%$ of the subjects were stable normotensive). The least prevalent MetS feature was low HDL-cholesterol (18.7\% were stable for low HDL and $64.1 \%$ were stable for high HDL). The most frequent combination of co-occurring MetS features was hypertension and abdominal obesity
(14.5\% were stable positive, $21.2 \%$ were stable negative). The least frequent combination was decreased HDLcholesterol levels and hyperglycemia (3.5\% were stable positive, $32.6 \%$ were stable negative).

19 SNPs were related to at least one of the stable MetS features with $\mathrm{P}<0.01$ (table 2). Two of them, Ile405 Val (rs5882) in the Cholesteryl Ester Transfer Protein (CETP) gene and Cys112Arg (rs429358) in the Apolipoprotein E (APOE) gene were related to $2 \mathrm{MetS}$ features each with $\mathrm{P}$ $<0.01$. This number differs significantly from the expected 0.12 SNPs to be associated with two features or more by chance alone $(\mathrm{p}<0.005$ chi-square with Yates correction). Both SNPs were in HWE (Ile405 Val P = 0.21; Cys112Arg P = 0.48). The minor Val allele of Ile405$\mathrm{Val}$ in the CETP gene was associated with both a decreased prevalence of low HDL-cholesterol levels (PR/ allele $0.76,95 \% \mathrm{CI} 0.69 ; 0.86)$ and a decreased prevalence of abdominal obesity (PR/allele $0.90,95 \% \mathrm{CI} 0.83$; 0.97) (table 3). The minor Arg allele of the Cys112Arg in the $A P O E$ gene was associated with an increased prevalence of low HDL-cholesterol levels (PR/allele 1.21, 95\% CI $1.07 ; 1.37)$ and an increased prevalence of abdominal obesity (PR/allele 1.12, 95\% CI 1.03; 1.23) (table 4). Results for both SNPs remained significant after adjusting the abdominal obesity analyses for HDL-cholesterol and vice versa. Further analyses showed that both SNPs were associated with the simultaneous occurrence of abdominal obesity and low HDL-cholesterol levels, with decreased HDL-cholesterol levels in a subgroup of people without abdominal obesity, and with abdominal obesity in a subgroup of people with normal HDL-cholesterol levels (table 3; table 4).

The Cys112Arg genotype of the APOE gene is part of the $\varepsilon 2, \varepsilon 3, \varepsilon 4$ haplotype. Results of the $\varepsilon 2 \varepsilon 3 \varepsilon 4$ haplotype analyses were similar to the results of the Cys112Arg analyses. Compared to the $\varepsilon 3 / \varepsilon 3$ isoform, the $\varepsilon 4 /$ - isoforms $(\varepsilon 3 / \varepsilon 4$ and $\varepsilon 4 / \varepsilon 4)$ were associated with an increased prevalence of low HDL-cholesterol levels (PR $1.24,95 \% \mathrm{CI} 1.07 ; 1.44)$ and an increased prevalence of abdominal obesity (PR 1.13, 95\%CI 1.01; 1.26). No associations were found with the $\varepsilon 2 /$ - isoforms $(\varepsilon 3 / \varepsilon 2$ and $\varepsilon 2 / \varepsilon 2)$.

\section{Discussion}

In this explorative study of 373 SNPs, mainly located in pathways related to lipid and glucose metabolism, we found a significant association between the Ile405 $\mathrm{Val}$ genotype in the CETP gene and the Cys112Arg genotype in the $A P O E$ gene, with multiple features of the metabolic syndrome, i.e. the prevalence of abdominal obesity and prevalence of low HDL-cholesterol. For both SNPs, the association with abdominal obesity was partly independent of the association with HDL-cholesterol, and 
Table 1 Characteristics of 3575 subjects of the Doetinchem Cohort in round 2 and 3

\begin{tabular}{|c|c|c|}
\hline & Round 2: 1993-1997 & Round 3: 1998-2002 \\
\hline Age (yr) & $46.5(9.7)$ & $51.5(9.7)$ \\
\hline Sex (\% men) & 47.8 & 47.8 \\
\hline Waist circumference (cm) & $90.2(11.1)$ & $92.9(11.4)$ \\
\hline Increased waist circumference (\%) ${ }^{a}$ & 31.3 & 40.3 \\
\hline Glucose levels $(\mathrm{mmol} / \mathrm{L})^{\mathrm{b}}$ & $5.3(1.3)$ & $5.4(1.5)$ \\
\hline Diabetic medication (\%) & 0.8 & 2.3 \\
\hline Hyperglycemia (\%) & 28.8 & 33.6 \\
\hline HDL-cholesterol (mmol/L) & $1.38(0.38)$ & $1.37(0.39)$ \\
\hline Low HDL-cholesterol (\%) ${ }^{a}$ & 25.4 & 29.0 \\
\hline Diastolic Blood Pressure (mm Hg) & $79.9(10.6)$ & $81.4(10.7)$ \\
\hline Systolic Blood Pressure (mm Hg) & $125.1(16.4)$ & $129.3(18.01)$ \\
\hline Hypertension (\%) ${ }^{a}$ & 50.8 & 58.5 \\
\hline Blood Pressure lowering medication (\%) & 6.5 & 11.0 \\
\hline MetS-score (number of features) & $1.34(1.1)$ & $1.61(1.1)$ \\
\hline Metabolic syndrome prevalence (\%) & 14.9 & 22.7 \\
\hline
\end{tabular}

Data are presented as means (standard deviation) or \%

${ }^{a}$ Abdominal obesity, hyperglycemia, low HDL, hypertension and MetS are defined according to the criteria of AHA-NHLBI (2005). Abdominal obesity: $\mathrm{O}^{\prime \prime} \geq 102 \mathrm{~cm}$; O $\geq 88 \mathrm{~cm}$; Low HDL: $0^{n}<1.0 ;$; $<1.3 \mathrm{mmol} / \mathrm{L}$; hypertension: $\geq 130 / 85 \mathrm{~mm} \mathrm{Hg}$ or hypertensive medicine; Hyperglycemia $\geq 5.6$ (mmol/L) or glucose lowering medication; MetS is defined as having 3 MetS features measured in Doetinchem Cohort

${ }^{b}$ Non-fasting values

Table 2 SNP's associated ( $P$ < 0.01) with stable MetS features among subjects of the Doetinchem Cohort over 2 surveys (1993-1997; 1998-2002)

\begin{tabular}{|c|c|c|c|c|}
\hline SNP & MAF & Gene & PR/allele (95\%CI) & P-Value \\
\hline \multicolumn{5}{|c|}{ Hyperglycemia ( $n=2280$ ) } \\
\hline rs1137101 & 0.46 & LEPR & $0.84(0.76 ; 0.93)$ & 0.001 \\
\hline rs3842748 & 0.21 & INS-IGF2 & $1.20(1.07 ; 1.35)$ & 0.002 \\
\hline rs6795441 & 0.45 & RAF1 & $0.86(0.77 ; 0.95)$ & 0.003 \\
\hline rs7903146 & 0.29 & TCF7L2 & $1.17(1.05 ; 1.30)$ & 0.005 \\
\hline rs1143634 & 0.24 & IL1B & $1.17(1.05 ; 1.31)$ & 0.005 \\
\hline \multicolumn{5}{|c|}{ Abdominal obesity $(n=2931)$} \\
\hline rs35724 & 0.38 & $\mathrm{NR} 1 \mathrm{H} 4$ & $0.91(0.85 ; 0.97)$ & 0.005 \\
\hline rs10860603 & 0.14 & $\mathrm{NR} 1 \mathrm{H} 4$ & $0.86(0.78 ; 0.96)$ & 0.006 \\
\hline rs1800796 & 0.04 & IL6 & $0.77(0.64 ; 0.93)$ & 0.007 \\
\hline rs5882 & 0.31 & CETP & $0.90(0.83 ; 0.97)$ & 0.007 \\
\hline rs429358 & 0.16 & APOE & $1.12(1.03 ; 1.23)$ & 0.007 \\
\hline \multicolumn{5}{|c|}{ Hypertension ( $n=2643$ ) } \\
\hline rs130005 & 0.10 & CREBBP & $0.89(0.82 ; 0.97)$ & 0.006 \\
\hline rs3759324 & 0.25 & SCCN1A & $1.07(1.02 ; 1.12)$ & 0.009 \\
\hline \multicolumn{5}{|c|}{ Low HDL-Cholesterol $(n=2959)$} \\
\hline rs1800777 & 0.03 & CETP & $1.60(1.56 ; 2.32)$ & $3.3 \mathrm{E}-12$ \\
\hline rs3208305 & 0.30 & LPL & $0.70(0.63 ; 0.79)$ & $9.3 \mathrm{E}-10$ \\
\hline rs328 & 0.11 & $L P L$ & $0.60(0.49 ; 0.72)$ & $1.2 \mathrm{E}-7$ \\
\hline rs5882 & 0.31 & CETP & $0.76(0.69 ; 0.86)$ & $2.1 \mathrm{E}-6$ \\
\hline rs429358 & 0.16 & APOE & $1.21(1.07 ; 1.37)$ & 0.001 \\
\hline rs174546 & 0.33 & FADS1 & $1.18(1.07 ; 1.30)$ & 0.001 \\
\hline rs780094 & 0.36 & GCKR & $1.17(1.06 ; 1.29)$ & 0.002 \\
\hline rs268 & 0.02 & LPL & $1.45(1.12 ; 1.86)$ & 0.004 \\
\hline rs5275 & 0.31 & PTGS2 & $1.15(1.04 ; 1.27)$ & 0.006 \\
\hline
\end{tabular}

MAF = Minor allele frequency; PR = Prevalence Ratio; ${ }^{\mathrm{b}}$ Prevalence ratios are expressed per minor allele assuming an additive genetic model vice versa. No, association was found between SNPs in genes involved in glucose metabolism or blood pressure regulation and multiple MetS features.

In humans, CETP and ApoE are expressed in the liver and in peripheral tissues, such as adipose tissue $[13,14]$. Both genes are involved in plasma lipid homeostasis. CETP stimulates the clearance of HDL-cholesterol from plasma [14]. Furthermore, CETP increases the formation of small dense LDL particles and triglycerides [15]. ApoE removes atherogenic lipoproteins, such as VLDL, from the circulation [16]. This results in lower cholesterol and triglyceride levels. Besides having a role in lipid homeostasis, a few studies indicate that CETP and ApoE may be involved in other metabolic processes such as weight regulation. For example, APOE plays a role in the deposition of dietary fat in adipose tissue [17]. As CETP is synthesized in the adipose tissue, CETP may affect adipose tissue characteristics [18].

The Ile405 Val polymorphism in the CETP gene induces a change in amino acid sequence. Therefore it is likely to be a functional SNP. In our study, the Val allele of the Ile $405 \mathrm{Val}$ genotype was associated with a lower prevalence of abdominal obesity and a lower prevalence of low HDL-cholesterol levels. The stratified and adjusted analyses in our study suggested that the association with prevalence of abdominal obesity and prevalence of low HDL-cholesterol levels was partly independent of each other. This suggests that CETP regulates weight and HDL-cholesterol via independent pathways. 
Table 3 Association of Ile405Val (rs5882) in the CETP gene with abdominal obesity and low HDL-cholesterol levels

\begin{tabular}{|c|c|c|c|c|c|}
\hline Outcome $^{a}$ & Ile/lle & Ile/Val & $\mathrm{Val} / \mathrm{Val}$ & PR/allele $(95 \% \mathrm{Cl})^{\mathrm{b}}$ & P-trend \\
\hline \multicolumn{6}{|l|}{ Prevalence of low $\mathrm{HDL}^{\mathrm{c}}$} \\
\hline $\begin{array}{l}\text { Overall } \\
(n=669, \text { total } n=2959)\end{array}$ & $26.0 \%$ & $20.6 \%$ & $14.4 \%$ & $0.76(0.69 ; 0.86)$ & $<.0001$ \\
\hline $\begin{array}{l}\text { Adjusted for abdominal obesity } \\
(n=669 \text {, total } n=2959)\end{array}$ & $24.7 \%$ & $21.3 \%$ & $16.0 \%$ & $0.83(0.74 ; 0.93)$ & 0.002 \\
\hline $\begin{array}{l}\text { Among subjects without abdominal obesity } \\
(n=252 \text {, total } n=1684)\end{array}$ & $18.4 \%$ & $13.0 \%$ & $7.8 \%$ & $0.68(0.56 ; 0.82)$ & $<0.001$ \\
\hline \multicolumn{6}{|l|}{ Prevalence of abdominal obesity ${ }^{d}$} \\
\hline $\begin{array}{l}\text { Overall } \\
(n=958, \text { total } n=2931)\end{array}$ & $34.7 \%$ & $31.9 \%$ & $26.4 \%$ & $0.90(0.83 ; 0.97)$ & 0.0072 \\
\hline $\begin{array}{l}\text { Adjusted for low HDL } \\
(n=958, \text { total } n=2931)\end{array}$ & $33.1 \%$ & $30.4 \%$ & $27.0 \%$ & $0.92(0.83 ; 1)$ & 0.05 \\
\hline $\begin{array}{l}\text { Among subjects with high HDL levels } \\
(n=470 \text {, total } n=1902)\end{array}$ & $27.9 \%$ & $22.8 \%$ & $18.7 \%$ & $0.82(0.73 ; 0.93)$ & 0.0014 \\
\hline \multicolumn{6}{|c|}{ Prevalence of both low HDL and abdominal obesity } \\
\hline $\begin{array}{l}\text { Overall } \\
(n=298, \text { total } n=1730)\end{array}$ & $19.5 \%$ & $16.3 \%$ & $11.2 \%$ & $0.81(0.69 ; 0.94)$ & 0.0076 \\
\hline
\end{tabular}

PR = Prevalence Ratio

a All analyses are adjusted for age and sex

b Prevalence ratios are expressed per minor VAL allele assuming an additive genetic model

c Subjects with low HDL-cholesterol in round 2, but not in round 3 or vice versa, were excluded

d Subjects with abdominal obesity in round 2 , but not round 3 or vice versa, were excluded

e Only subjects with either both abdominal obesity and low HDL-cholesterol levels in round 2 and 3 or with both no abdominal obesity and high HDL-

cholesterol levels were included. Subjects without abdominal obesity and with high HDL-cholesterol levels in round 2 and 3 were used as the reference category

In line with our results, a meta-analysis of 29 studies, showed that $\mathrm{Val}$ allele carriers had higher HDL levels [19]. Furthermore, a Chinese case-control study in 934 obesity cases and 924 controls showed a decreased obesity risk for $\mathrm{Val} / \mathrm{Val}$ homozygotes, which persisted after adjustment for HDL-cholesterol levels [20]. In previous studies, the $405 \mathrm{Val}$ allele has been associated with lower CETP mass and lower CETP activity [19]. Lower CETP plasma levels are correlated with a lower obesity risk [21]. The $405 \mathrm{Val}$ allele has also been associated with

Table 4 Association of Cys112Arg (rs429358) in the APOE gene with abdominal obesity and low HDL-cholesterol levels

\begin{tabular}{|c|c|c|c|c|c|}
\hline Outcome $^{a}$ & Cys/Cys & Cys/Arg & Arg/Arg & PR/allele $(95 \% \mathrm{Cl})^{\text {b }}$ & P-trend \\
\hline \multicolumn{6}{|l|}{ Prevalence of low $\mathrm{HDL}^{\mathrm{c}}$} \\
\hline $\begin{array}{l}\text { Overall } \\
(n=669, \text { total } n=2959)\end{array}$ & $21.2 \%$ & $25.5 \%$ & $32.3 \%$ & $1.21(1.07 ; 1.37)$ & 0.0013 \\
\hline $\begin{array}{l}\text { Adjusted for abdominal obesity } \\
(n=669 \text {, total } n=2959)\end{array}$ & $21.0 \%$ & $25.5 \%$ & $30.2 \%$ & $1.20(1.06 ; 1.36)$ & 0.005 \\
\hline $\begin{array}{l}\text { Among subjects without abdominal obesity } \\
(n=252 \text {, total } n=1684)\end{array}$ & $13.5 \%$ & $18.0 \%$ & $26.0 \%$ & $1.35(1.11 ; 1.65)$ & 0.0031 \\
\hline \multicolumn{6}{|l|}{ Prevalence of abdominal obesity ${ }^{d}$} \\
\hline $\begin{array}{l}\text { Overall } \\
(n=958, \text { total } n=2931)\end{array}$ & $31.2 \%$ & $35.8 \%$ & $39.6 \%$ & $1.12(1.03 ; 1.23)$ & 0.0074 \\
\hline $\begin{array}{l}\text { Adjusted for low HDL } \\
(n=958, \text { total } n=2931)\end{array}$ & $30.1 \%$ & $33.1 \%$ & $38.9 \%$ & $1.12(1.01 ; 1.25)$ & 0.04 \\
\hline $\begin{array}{l}\text { Among subjects with high HDL levels } \\
(n=470 \text {, total } n=1902)\end{array}$ & $23.5 \%$ & $27.3 \%$ & $34.5 \%$ & $1.16(1.01 ; 1.33)$ & 0.03 \\
\hline \multicolumn{6}{|c|}{ Prevalence of both low HDL and abdominal obesity } \\
\hline $\begin{array}{l}\text { Overall } \\
(n=298, \text { total } n=1730)\end{array}$ & $15.7 \%$ & $20.7 \%$ & $27.8 \%$ & $1.29(1.08 ; 1.54)$ & 0.0045 \\
\hline
\end{tabular}

PR = Prevalence Ratio

${ }^{\text {a All }}$ analyses are adjusted for age and sex

${ }^{\mathrm{b}}$ Prevalence ratios are expressed per minor ARG allele assuming an additive genetic model

c Subjects with low HDL-cholesterol in round 2, but not in round 3 or vice versa, were excluded

d Subjects with abdominal obesity in round 2 , but not round 3 or vice versa, were excluded

e Only subjects with either both abdominal obesity and low HDL-cholesterol levels in round 2 and 3 or with both no abdominal obesity and high HDL-

cholesterol levels were included. Subjects without abdominal obesity and with high HDL-cholesterol levels in round 2 and 3 were used as the reference category 
other positive health outcomes such as, increased HDL and LDL particle size [15], decreased coronary heart disease risk [22], and increased longevity [15], all of which are related to the MetS. In summary, cumulative evidence indicates that Ile405 Val is involved in several metabolic processes, including lipid level control and weight regulation.

The Cys112Arg genotype of the APOE gene is a nonsynonymous genotype. Together with Arg158Cys (rs7412), the Cys112Arg forms the $\varepsilon 2 \varepsilon 3 \varepsilon 4$ haplotype. The $\varepsilon 2, \varepsilon 3$ and $\varepsilon 4 \mathrm{ApoE}$ isoforms differ markedly on the structural and functional level [16]. In our study the $\mathrm{Arg}$ allele of the Cys112Arg genotype was associated with an increased prevalence of low HDL-cholesterol levels and an increased prevalence of abdominal obesity. Again the stratified and adjusted analyses suggested that the associations with the prevalence of abdominal obesity and prevalence of low HDL-cholesterol levels were partly independent of each other. The $\varepsilon 4$ isoform showed a similar, though less pronounced, pattern of associations. No associations were observed with Arg158Cys or $\varepsilon 2$ isoform, of the $\varepsilon 2 \varepsilon 3 \varepsilon 4$ haplotype.

Previous studies generally focused on the $\varepsilon 2, \varepsilon 3$ and $\varepsilon 4$ haplotype and did not take associations with the individual Arg158Cys and Cys112Arg into account. In line with our study, the $\varepsilon 4$ isoform was associated with a more detrimental metabolic profile in most studies. A meta-analysis of 19 studies in 9751 subjects, showed that $\varepsilon 3 / \varepsilon 4$ carriers had lower HDL-cholesterol levels than $\varepsilon 3 / \varepsilon 3$ carriers [23]. Most studies showed either a positive [24-27] or no [28-31] association between the $\varepsilon 4$ isoform and body weight. However, some showed a negative association [30,31]. Arbones Mainar et al. [28] showed that compared to ApoE3 mice, ApoE4 mice fed a western diet were more prone to the development of several MetS features, such as increased insulin resistance, decreased fat tolerance and increased fat cell size. However, they gained less body weight. This suggests that the positive association between the $\varepsilon 4$ isoform and abdominal obesity may be driven by the development of other MetS features, such as insulin resistance [28]. Furthermore, these results suggest that the $\varepsilon 4$ isoform may be associated with MetS. This has indeed been shown in other epidemiological studies $[25,26,29]$.

Strength of our pathway driven candidate gene study was the relatively large sample size. Contrast and precision were increased by exclusively including people with consistent MetS phenotype, i.e. classified as healthy or not healthy for a particular metabolic phenotype over two measurement rounds. Furthermore we tried to keep the probability of chance findings low by including only those SNPS that were related to two or more MetS features with $\mathrm{P}<0.01$ into the second round of data-analysis. We found
2 SNPs, which differed significantly from the expected 0.12 SNPs ( $p<0.005$ chi-square with Yates correction). However, the 0.12 expected SNPs were obtained assuming independent random outcomes. As HDL-cholesterol and abdominal obesity are not completely independent, this assumption is partly violated. However, the associations with abdominal obesity and HDL-cholesterol remained significant in our stratified and adjusted analyses. A weakness of our study may be that blood samples were taken from non-fasting subjects. This may have randomly affected the glucose measurements. Another weakness is that triglycerides levels were not measured in our study. Therefore, we may have missed SNPs which were related to hypertriglyceridemia and one or two other MetS feature. For example, the CETP Ile405 Val mutation has been associated with triglycerides in previous studies [19]. We therefore expect that in our study population this SNP will not only be associated with HDL-cholesterol and abdominal obesity, but also with triglyceride levels.

In this explorative study of 373 SNPs among 3575 subjects, we emphasized on the intricate links between several MetS features. We have showed that two SNPs, mainly known for their role in lipid metabolism, influenced both abdominal obesity and low HDL-cholesterol levels, partly independent of each phenotype. If the pleiotropic effects of these genes are further confirmed by others it might be possible to develop medication which increases HDL-cholesterol leves and reduces waist circumference, and so affects the development of MetS

\section{Acknowledgements}

The Doetinchem Cohort Study was financially supported by the Ministry of Health, Welfare and Sport of The Netherlands and the National Institute for Public Health and the Environment. The authors thank the epidemiologists and fieldworkers of the Municipal Health Service in Doetinchem for their contribution to the data collection for this study. Project director is Dr WMM Verschuren. Logistic management was provided by J Steenbrink and P Vissink, and administrative support by EP van der Wolf. Data management was provided by A Blokstra, AWD van Kessel and PE Steinberger. Genotyping facilities were provided by C Wijmenga. Technical assistance was provided by HM Hodemaekers and C. Strien.

\section{Author details}

${ }^{1}$ Centre for Nutrition and Health (CVG), National Institute for Public Health and the Environment (RIVM), Bilthoven, the Netherlands. ${ }^{2}$ Division of Human Nutrition, Wageningen University, Wageningen, the Netherlands. ${ }^{3}$ Laboratory for Health Protection Research (GBO), National Institute for Public Health and the Environment (RIVM), Bilthoven, the Netherlands.

\section{Authors' contributions}

METD, JMAB, EJMF and SI participated in performing the research. CMP JMAB and EJMF analyzed the data. All authors participated in interpretation of the data. CMP drafted the manuscript. All authors read and approved the final manuscript.

\section{Competing interests}

The authors declare that they have no competing interests.

Received: 2 June 2011 Accepted: 18 July 2011 Published: 18 July 2011 


\section{References}

1. Teran-Garcia M, Bouchard C: Genetics of the metabolic syndrome. App Physiol Nutr Metab 2007, 32:89-114

2. Hong Y, Pedersen NL, Brismar K, de Faire U: Genetic and environmental architecture of the features of the insulin-resistance syndrome. Am J Hum Genet 1997, 60:143-152.

3. Bellia A, Giardina E, Lauro D, Tesauro M, Di Fede G, Cusumano G, Federici M, Rini GB, Novelli G, Lauro R, Sbraccia P: "The Linosa Study": Epidemiological and heritability data of the metabolic syndrome in a Caucasian genetic isolate. Nutr Metab Cardiovasc Dis 2009

4. Bosy-Westphal A, Onur S, Geisler C, Wolf A, Korth O, Pfeufferm M, Schrezenmeir J, Krawczak M, Muller MJ: Common familial influences on clustering of metabolic syndrome traits with central obesity and insulin resistance: the Kiel obesity prevention study. Int J Obes (Lond) 2007, 31:784-790.

5. Henneman P, Aulchenko YS, Frants RR, van Dijk KW, Oostra BA, van Duijn CM: Prevalence and heritability of the metabolic syndrome and its individual components in a Dutch isolate: the Erasmus Rucphen Family study. J Med Genet 2008, 45:572-577.

6. Carmelli D, Cardon LR, Fabsitz R: Clustering of hypertension, diabetes, and obesity in adult male twins: same genes or same environments? Am J Hum Genet 1994, 55:566-573.

7. Benyamin B, Sorensen TIA, Schousboe K, Fenger M, Visscher PM, Kyvik KO: Are there common genetic and environmental factors behind the endophenotypes associated with the metabolic syndrome? Diabetologia 2007, 50:1880-1888.

8. Lusis AJ, Alan DA, Reue K: Metabolic syndrome: from epidemiology to systems biology. Nat Rev Genet 2008, 9:819-830.

9. van Dam RM, Boer JM, Feskens EJ, Seidell JC: Parental history of diabetes modifies the association between abdominal adiposity and hyperglycemia. Diabetes Care 2001, 24:1454-1459.

10. van den Berg SW, Dolle ME, Imholz $S$, van der $A D$, van 't Slot $R$ Wijmenga C, Verschuren WM, Strien C, Siezen CL, Hoebee B, Feskens EJ, Boer JM: Genetic variations in regulatory pathways of fatty acid and glucose metabolism are associated with obesity phenotypes: a population-based cohort study. Int J Obes (Lond) 2009, 33:1143-1152.

11. Povel CM, Feskens EJ, Imholz S, Blaak EE, Boer JM, Dolle ME: Glucose levels and genetic variants across transcriptional pathways: interaction effects with BMI. Int J Obes 2010, 34:840-5.

12. Grundy SM, Cleeman II, Daniels SR, Donato KA, Eckel RH, Franklin BA, Gordon DJ, Krauss RM, Savage PJ, Smith SC Jr, Spertus JA, Costa F: Diagnosis and management of the metabolic syndrome. An American Heart Association/National Heart, Lung, and Blood Institute Scientific Statement. Executive summary. Cardiol Rev 2005, 13:322-327.

13. Pendse AA, Arbones-Mainar JM, Johnson LA, Altenburg MK, Maeda N: Apolipoprotein E knock-out and knock-in mice: atherosclerosis, metabolic syndrome, and beyond. J Lipid Res 2009, 50:S178-182.

14. Zhou H, Li Z, Hojjati MR, Jang D, Beyer TP, Cao G, Tall AR, Jiang XC: Adipose tissue-specific CETP expression in mice: impact on plasma lipoprotein metabolism. J Lipid Res 2006, 47:2011-2019.

15. Barzilai N, Atzmon G, Schechter C, Schaefer EJ, Cupples AL, Lipton R, Cheng S, Shuldiner AR: Unique lipoprotein phenotype and genotype associated with exceptional longevity. JAMA 2003, 290:2030-2040.

16. Greenow K, Pearce NJ, Ramji DP: The key role of apolipoprotein E in atherosclerosis. J Mol Med 2005, 83:329-342.

17. Karagiannides I, Abdou R, Tzortzopoulou A, Voshol PJ, Kypreos KE: Apolipoprotein $\mathrm{E}$ predisposes to obesity and related metabolic dysfunctions in mice. Febs J 2008, 275:4796-4809, Epub 2008 Aug 4727

18. Ka G, Going SB, Fernandez ML, Milliken LA, Lohman TG, Bassford T, McNamara DJ: Cholesteryl ester transfer protein and lecithin:cholesterol acyltransferase activities in hispanic and anglo postmenopausal women: associations with total and regional body fat. Metabolism 2003, $52: 282-289$

19. Thompson A, Di Angelantonio E, Sarwar N, Erqou S, Saleheen D, Dullaart RP, Keavney B, Ye Z, Danesh J: Association of cholesteryl ester transfer protein genotypes with CETP mass and activity, lipid levels, and coronary risk. JAMA 2008, 299:2777-2788.

20. Ruan X, Ma L, Wang S, Lindpaintner K, Liu X, Wang B, Peng Z, Ma X Cheng M, Zhang J, Liu L, Wang X: TAQIB and I405V polymorphisms of CETP are moderately associated with obesity risk in the Chinese adult population. Acta Diabetol 2009, 47:217-24
21. Arai T, Yamashita S, Hirano K, Sakai N, Kotani K, Fujioka S, Nozaki S, Keno Y, Yamane M, Shinohara E: Increased plasma cholesteryl ester transfer protein in obese subjects. A possible mechanism for the reduction of serum HDL cholesterol levels in obesity. Arterioscler Thromb 1994, 14:1129-1136.

22. Thompson JF, Durham LK, Lira ME, Shear C, Milos PM: CETP polymorphisms associated with HDL cholesterol may differ from those associated with cardiovascular disease. Atherosclerosis 2005, 181:45-53.

23. Dallongeville J, Lussier-Cacan S, Davignon J: Modulation of plasma triglyceride levels by apoE phenotype: a meta-analysis. J Lipid Res 1992, 33:447-454.

24. Oh JY, Barrett-Connor E: Apolipoprotein E polymorphism and lipid levels differ by gender and family history of diabetes: the Rancho Bernardo Study. Clin Genet 2001, 60:132-137.

25. Sima A, lordan A, Stancu C: Apolipoprotein E polymorphism-a risk factor for metabolic syndrome. Clin Chem Lab Med 2007, 45:1149-1153.

26. Srinivasan SR, Ehnholm C, Wattigney WA, Bao W, Berenson GS: The relation of apolipoprotein $\mathrm{E}$ polymorphism to multiple cardiovascular risk in children: the Bogalusa Heart Study. Atherosclerosis 1996, 123:33-42.

27. Srivastava N, Achyut BR, Prakash J, Agarwal CG, Pant DC, Mittal B: Association of cholesteryl ester transfer protein (TaqlB) and apolipoprotein $\mathrm{E}$ (Hhal) gene variants with obesity. Mol Cell Biochem 2008, 314:171-177.

28. Arbones-Mainar JM, Johnson LA, Altenburg MK, Maeda N: Differential modulation of diet-induced obesity and adipocyte functionality by human apolipoprotein E3 and E4 in mice. Int J Obes (Lond) 2008, 32:1595-1605.

29. Olivieri O, Martinelli N, Bassi A, Trabetti E, Girelli D, Pizzolo F, Friso S, Pignatti PF, Corrocher R: ApoE epsilon2/epsilon3/epsilon4 polymorphism, ApoC-III/ApoE ratio and metabolic syndrome. Clin Exp Med 2007, 7:164-172.

30. Pardo Silva MC, Janssens AC, Hofman A, Witteman JC, van Duijn CM: Apolipoprotein $\mathrm{E}$ gene is related to mortality only in normal weight individuals: the Rotterdam Study. Eur J Epidemiol 2008, 23:135-142.

31. Volcik KA, Barkley RA, Hutchinson RG, Mosley TH, Heiss G, Sharrett AR, Ballantyne CM, Boerwinkle E: Apolipoprotein E polymorphisms predict low density lipoprotein cholesterol levels and carotid artery wall thickness but not incident coronary heart disease in 12,491 ARIC study participants. Am J Epidemiol 2006, 164:342-348.

doi:10.1186/1476-511X-10-118

Cite this article as: Povel et al:: Genetic variants in lipid metabolism are independently associated with multiple features of the metabolic syndrome. Lipids in Health and Disease 2011 10:118.

\section{Submit your next manuscript to BioMed Central and take full advantage of:}

- Convenient online submission

- Thorough peer review

- No space constraints or color figure charges

- Immediate publication on acceptance

- Inclusion in PubMed, CAS, Scopus and Google Scholar

- Research which is freely available for redistribution
C Biomed Central 